\title{
Surface Morphology Analysis of Ti-6Al-4V, V-4Ti-5Cr, and Molybdenum Exposed to Low Power Nd: YAG Laser
}

\author{
H. Aglan ${ }^{1}$, A. Kumar ${ }^{1}$, K. Muir ${ }^{1}$ and A. Hassanein ${ }^{2}$ \\ ${ }^{1}$ Tuskegee University, Tuskegee, AL, USA \\ ${ }^{2}$ Purdue University, West Lafayette, Indiana, USA
}

Titanium, Vanadium, and Molybdenum alloys are favorable candidate materials for many applications in extreme environments. These include nuclear fusion and fission reactor systems, biomedical applications, aeronautical and aerospace industries, and high temperature industrial applications [1-3]. In this study, the effect of laser exposure time on the surface morphology of the Ti-6Al-4V, V-4Ti-5Cr, and pure Mo were examined using Scanning Electron Microscopy. An Nd: YAG (Neodymium-doped Yttrium Aluminum Garnet; Nd: $\mathrm{Y}_{3} \mathrm{Al}_{5} \mathrm{O}_{12}$ ) laser (model Quantel Big Sky CFR 200) was used. The specimens were exposed to radiation with a wavelength of $1064 \mathrm{~nm}$ and pulse duration of approximately $9.2 \mathrm{~ns}$ at beam energy of about $185 \mathrm{~mJ}$ and a spot size of $5.4 \mathrm{~mm}$. The frequency of the laser was $20 \mathrm{~Hz}$ with an approximately Gaussian profile. Based on observed spot size of $5.4 \mathrm{~mm}$ the laser energy density (per pulse) and average power density has been calculated as $0.808 \mathrm{~J} / \mathrm{cm}^{2}$ and $16.16 \mathrm{~W} / \mathrm{cm}^{2}$. Rectangular specimens of $75 \times 12.7 \times 0.81 \mathrm{~mm}$ from each material were exposed for 5 minutes and 15 minutes. A Hitachi S-3400N SEM was used to examine the surface morphological evolution.

The micrographs in Figure 1a, b, and c are for 5 minutes laser exposure of Titanium, Vanadium, and Molybdenum respectively, while those in Figure 2a, b, and c are for 15 minutes exposure. Three different zone structures in the exposed area with different morphological features are shown in these micrographs. These zones are created after rapid superheating and movement of melt surface material to create ripples.

Titanium, Figure 1a, shows the most affected central zone. This contained the most bulges, which were formed from superheating that lead to phase change. The superheated areas were attributed to the spatial energy distribution of the interaction of the laser beam with the wavy/bubbly surface, Figure 1a. The ripples, along with the size and density of bulge microstructure, became deeper and wider with increased exposure time, figure $2 \mathrm{a}$. In the inner zone, particles were melted with no dominant bubbled microstructure. Vanadium, Figure 1b, shows similar features to those in Figure 1a for Titanium after 5 minutes of exposure, with less intensity of bulges in the central zone. The outer ablated zone was also less affected in the case of Vanadium. Similar features are shown in Figure $2 \mathrm{~b}$ as in Figure $2 \mathrm{a}$ after 15 minutes of exposure. Both $\mathrm{Ti}-6 \mathrm{Al}-4 \mathrm{~V}$ and $\mathrm{V}-4 \mathrm{Ti}-5 \mathrm{Cr}$ possessed dense micro bulges at the central zone. The average bulge diameter for Ti-6Al-4V and $\mathrm{V}-4 \mathrm{Ti}-5 \mathrm{Cr}$ was increased by $7 \mu \mathrm{m}$ and $24 \mu \mathrm{m}$ for exposure times of 5 and 15 minutes, respectively.

Molybdenum, Figure 1c and Figure 2c, displays a wave-like pattern on the surface "patterned ripples" for both 5 and 15 minutes laser exposures. It is observed that the ripple spacing and length of the ripple were increased with laser exposure time. The average ripple length of Mo for 5 and 15 minutes showed an increase of $30 \mu \mathrm{m}$. Mo with higher melting point suffered less vaporization but more melting.

The average melting temperatures for Ti-6Al-4V, V-4Ti-5Cr, and Mo are 1630, 1900, and $2620^{\circ} \mathrm{C}$ respectively. Both the melting point and the thermal properties can be correlated to the extent of surface erosion, melt depth, motion, and texturing of the materials under laser exposure [4]. 


\section{References:}

[1] I. Gurrappa, Materials Characterization, 51(2), (2003) p. 131.

[2] M. Victoria, N. Baluc, and P. Spatig, Structural materials for fusion reactors. (2001) p. 1047.

[3] P. Fischer et al., ActaMaterialia 51 (2003) p. 1651.

[4] This work is supported by NSF, Partnerships for International Research and Education (PIRE) project.
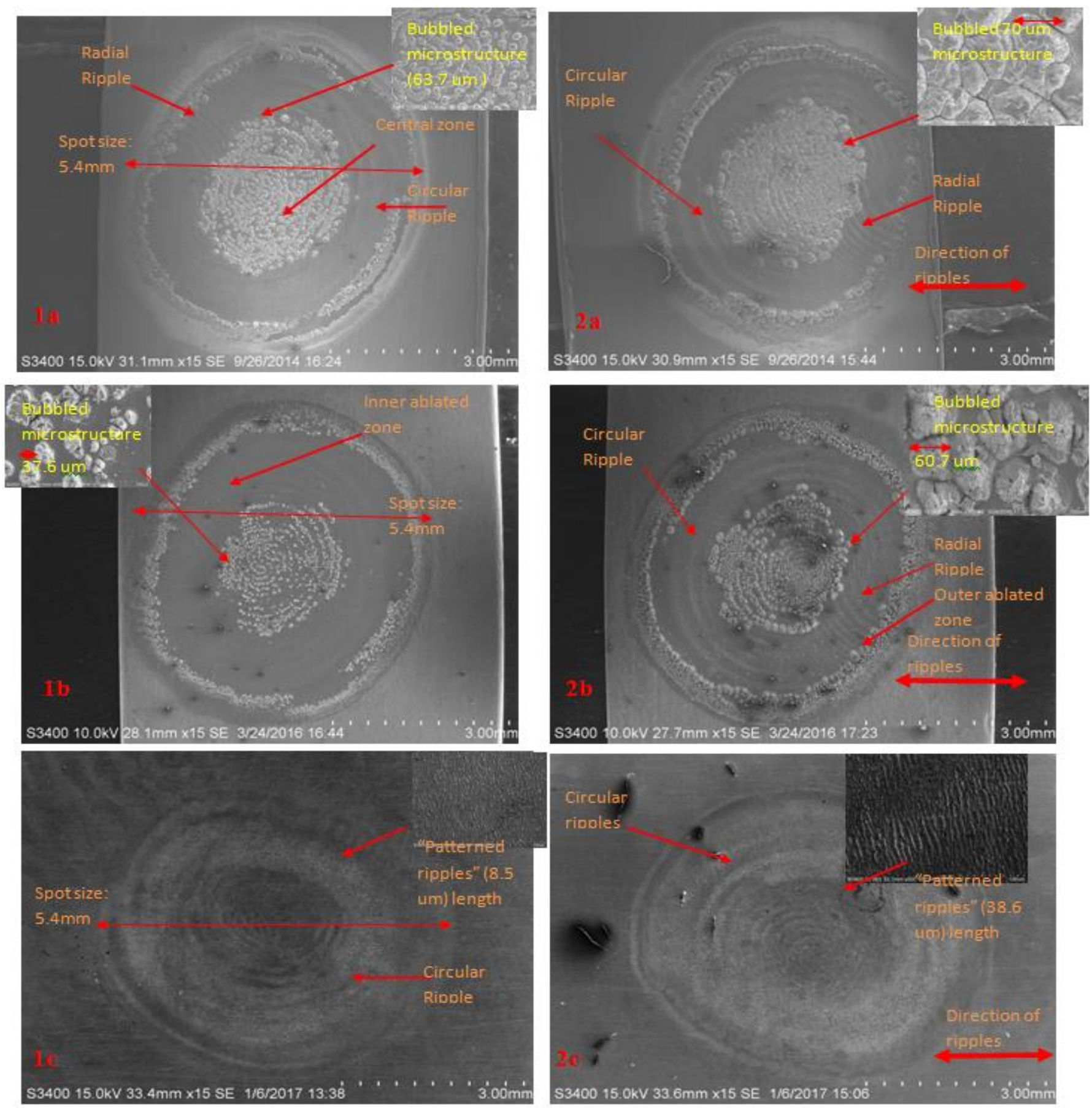

Fig 1. SEM analysis at $15 \mathrm{X}$ magnification after $5 \mathrm{~min}$ $\mathrm{Nd}$-YAG laser exposure for: a) $\mathrm{Ti}-6 \mathrm{Al}-4 \mathrm{~V}$, b) V-4Ti-5Cr and c) molybdenum.

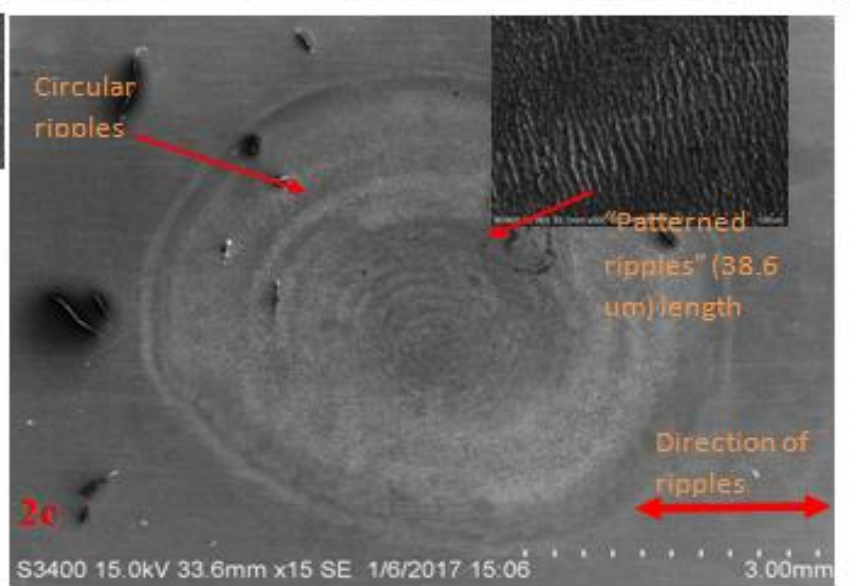

Fig. 2. SEM analysis at $15 \mathrm{X}$ magnification after $15 \mathrm{~min}$ $\mathrm{Nd}$-YAG laser exposure for: a) $\mathrm{Ti}-6 \mathrm{Al}-4 \mathrm{~V}$, b) $\mathrm{V}-4 \mathrm{Ti}-5 \mathrm{Cr}$ and c) molybdenum. 